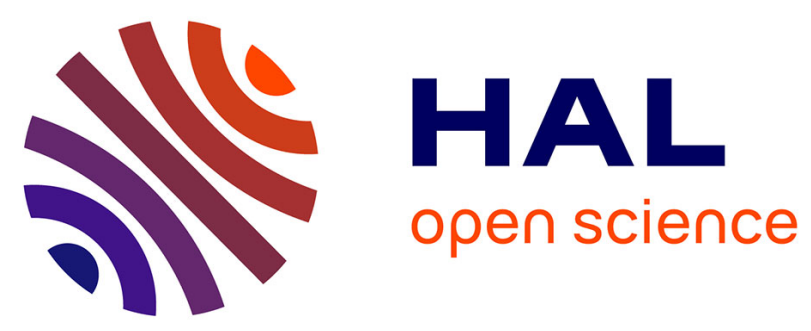

\title{
Improving Transport and Accessibility through New Communication Technologies
}

Jan Frick

\section{To cite this version:}

Jan Frick. Improving Transport and Accessibility through New Communication Technologies. IFIP International Conference on Advances in Production Management Systems (APMS), Sep 2014, Ajaccio, France. pp.572-578, 10.1007/978-3-662-44736-9_69 . hal-01387934

\section{HAL Id: hal-01387934 \\ https://inria.hal.science/hal-01387934}

Submitted on 26 Oct 2016

HAL is a multi-disciplinary open access archive for the deposit and dissemination of scientific research documents, whether they are published or not. The documents may come from teaching and research institutions in France or abroad, or from public or private research centers.
L'archive ouverte pluridisciplinaire HAL, est destinée au dépôt et à la diffusion de documents scientifiques de niveau recherche, publiés ou non, émanant des établissements d'enseignement et de recherche français ou étrangers, des laboratoires publics ou privés.

\section{(c)(1)}

Distributed under a Creative Commons Attribution| 4.0 International License 


\title{
Improving Transport and Accessibility through new Communication Technologies.
}

\author{
Jan Frick \\ University of Stavanger, Stavanger, Norway \\ jan.frick@uis.no
}

\begin{abstract}
The accessibility of regions regarding transport is a clear advantage in terms of their social-economic development. New technologies may improve the utilization and usability of public transport on a large scale. The ITRACT project investigates this by developing and testing applications for wireless communication regarding public transport.
\end{abstract}

Keywords: public transport; usability; wireless communication

\section{Introduction}

Regions want to develop, and the accessibility of regions is a clear advantage in terms of their social-economic development. With new technologies, such as satellite and integrated sensor networks, transport and accessibility of remote areas and functionality of transport in urban areas can be improved in innovative ways. This is a development that is going on in many regions. (Emmanouilidis et al., 2013) It is partly related to and dependent of the local access of wireless communication in the region and partly to the availability of Internet access in general.

There is also a clear difference on wanted functionality in urban versus rural areas. The urban issues might focus on reducing the effect of rush-hours, where the rural issues will focus more on how to make best use of less frequent public transportation. There is also a difference in need in the population as people commuting to work or studies will have different needs than other groups as retired people or tourists.

This is not a new concept as futuristic writers have written about such functionality in several decades. One of the most famous is Isaac Asimov that wrote for the World Fair in 1964 on prediction for the future 40 years ahead.

(Asimov, 1964) But now personalized interconnected mobile gadgets are available with a fast increasing functionality.(Klein, 2014, Gubbi, 2013)

\section{The ITRACT project}

The ITRACT project (Frick, 2014) was started in January 2012. It develops and test innovative tools for efficient, user- and environment-friendly transport networks across the North Sea Region. The aim is to create 
sustainable and inclusive regional economies and communities throughout the North Sea Region by improving the virtual and physical modes of transport on a large scale. The project is funded by the European Union "InterReg IVb NorthSea". (Interreg-IVb-NorthSea, 2014) The regions that participate are Groningen in Netherlands, Värmland in Sweden, Ems-Jade in Germany, Yorkshire in UK, and Rogaland in Norway. All regions participate with both county/ public transport administrator and university, except UK that have public transport administration only.

The project started out with a process to involve users of public transport and through workshops establishing priorities in each region. These were then grouped by functionality and programs (apps) to be developed were decided. Then some of the universities developed an architecture and following database to provide the different apps with a common backbone and thus achieve a higher functionality that what stand-alone apps might alone. The regions then defined how apps could be grouped in tests for functionality and usability, and these tests are due late 2014. (Frick, 2014)

The ITRACT project has during 2013 moved from the early stage of describing the need of the regions and brainstorming how to answer the prioritized issues. Now apps designed to be building blocks are under development and will be available for all regions as described in the defined priorities. These apps shall utilize WIFI communication to improve the public transport issues in the participating regions. The regions will test and utilize the apps in various ways depending on the need in each region.

\section{Rogaland}

\subsection{Scheduling app}

When ITRACT project started, it became clear that the public transport administrator in Rogaland County (Kolumbus) had a parallel activity in their own development process. In spring 2012 an app for scheduling was distributed for public use. It is available for iphone, android, and also available as a website.

The scheduling app utilizes Google Maps and Google Transit Feed Spesification Reference, GTFS. The use of GTFS enables the scheduling app to connect to other transport data in other regions. The consequence is that if you want to plan a travel from University of Stavanger to a location at University of Oslo, then the planner tells you where to walk to the bus stop, when next bus is expected due to schedule, when you can transfer from bus to next train to Oslo, when you can transfer to the local Oslo bus, where to stop, and where to walk to final location. All based on where you are and published schedules. Since 2012 the GTFS has become a standard for these types of mobile systems as most public transport companies need to 
exchange data with neighbouring regions to provide users with transferability options from one location to the next. The scheduling app had so far more than 3000 scheduling request per day in 2014 in a population of 300000 .

\subsection{Real-time app}
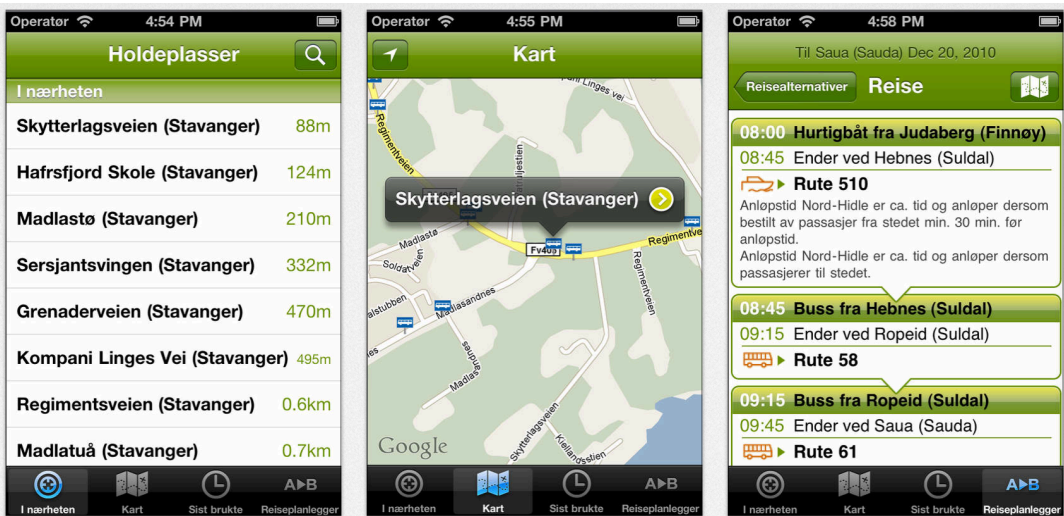

Figure 1: 3 iphone screen captures from Kolumbus scheduling app

Then in April 2013 a real-time app was distributed. This one does not plan your travel, but it identifies where you are with bus stops closest to you, and then tells you which busses will connect at that stop and when they are expected including delays. This real time functionality is available for iphone/ ipad, android, and general website. But the real-time information is also on screens at bus stops and on a screen in the busses. The real-time app is the most popular app as it enables its users to optimize their time due to better knowledge on actual transport options.

From the bus administrator, it can be seen as "High Resolution Supply Chain Management" similar to the model suggested by Volker Stich et al. (Volker Stich et al., 2011). Users tend to forget that a mobile app like this one includes much more that the map, locations, and time estimates that they see. Behind the scene are databases with schedules, locations, map references, historic data, and a continuous analysis of data and forecast of each bus that is in use. So included to the forecast presented to users, the drivers have a similar feedback on status versus schedule, and the bus administrators have a framework for allocating and optimizing all activities within the focus of published schedule.

The scheduling app is a simple case compared to the infrastructure behind the real-time app. In the scheduling app we have a schedule plan with its locations a related expected time and map references, but in the real-time app 
we have added dynamic collection of data, historic comparison, and a continuous analysis to be presented to users depending on their location. It is a complex cybernetic system.

The real-time app reached up to 220000 update clicks per week in April 2014.

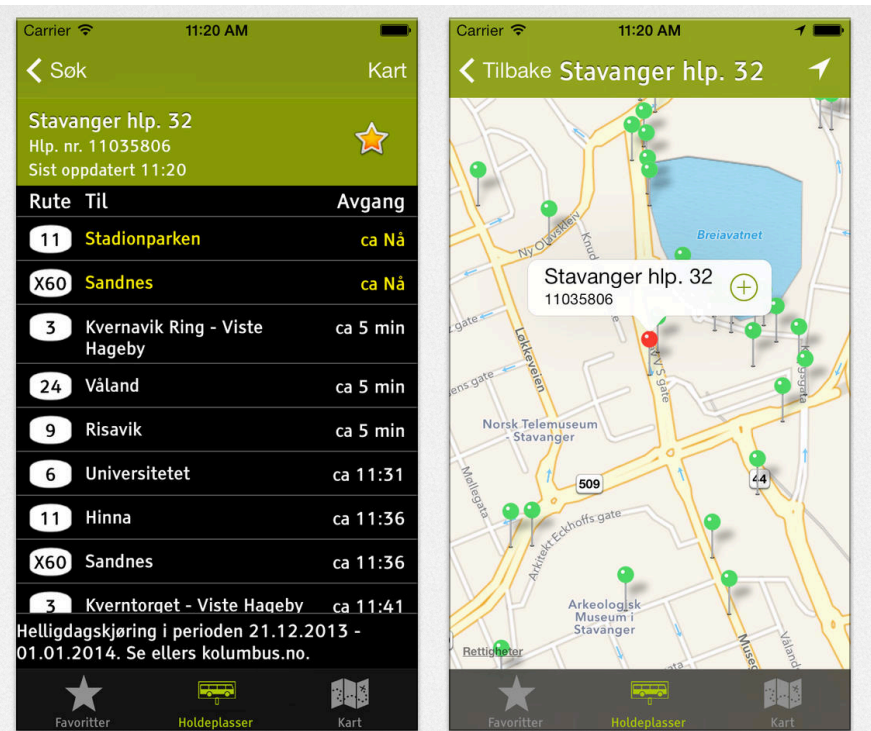

Figure 2: 2 iphone screen captures from Kolumbus real-time app

\subsection{Flexible payment app}

The flexible payment app was released in September 2013. It enables people with to enter a bus, pay with an iphone or android, and then show it to the bus-driver as one would do with a prepaid ticket.

This sounds easy, but the price to pay depends on zones included in the travel. So locations of start and end points and the identification of the busroute are included in the calculation. In the future, a development to move most or all passengers to cash free system may be provided, but for the moment only a single ride payment is in place. Users of rebated monthly payment and similar reduced fare options still have to use a traditional ticket or card.

The 3 apps have been very popular with estimated downloads of 80000 up to May 14 in a population of 300000 . The local ITRACT project group used a group of students in 2013 with a questionnaire to look for feedback about functionality and usability. This gave surprisingly little negative comments 
on functionality or usability. A survey to university employees and students in June 2014 showed $>60 \%$ of respondents as transport app users. $60 \%$ also indicated that such apps might increase their use of public transport. Next issues will be to further test the usability and functionality of these 3 apps more in detail with both the users in the region and to compare as far as possible with apps developed at the other ITRACT partner universities. The purpose of this is to see if or how functionality and usability can be improved. A possibility is also to merge the apps.
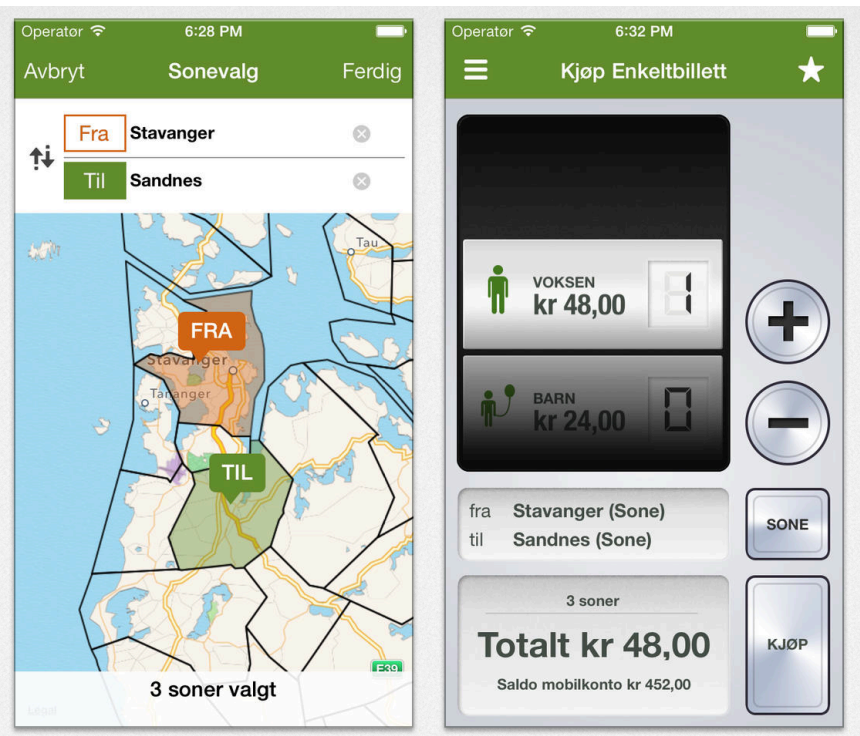

Figure 3: 2 iphone screen captures from Kolumbus flexible payment app

In addition, Rogaland County will test "Bus on Demand" or "Shared Ride" apps developed at the ITRACT partner universities. This is assumed to be able to offer an improved service for rural areas in periods of the day when busses have a lower frequency. A "Bus on Demand" app is supposed to run a planned route but collect and deliver passengers within an area close to the route. The route will then be run when a number of passengers have accumulated and passengers will get a response on when to expect to be collected. So this may become an app demanding to-way dialogue to group passengers and keep the flexibility. If this will work remains to see, but such an app is in development at ITRACT partners, and Rogaland county has such a functionality based on phones in a rural area of the county.

Other results from the June 2014 survey are that $60 \%$ would like that their employer might prepay their travel so an payment app could confirm this, 
and that $40 \%$ would like automatic payment from the app when they boarded the bus. This is technical feasible as the mobile phones can be identified in a similar way as RFID tags. RFID has two main tag technologies, which is active with a battery or inactive without. (Jones and Chung, 2011) The bus tickets or cards used contain RFID tags, and a similar identification can be made for phones. The registration within a certain distance from a reader is easy, but it may be more complex to register when a user is leaving if there are different zones with their own rate. And there is also a matter of security regarding tracking of user movements. Several comments in the June 2014 survey indicated wishes for better maps included where user location, the bus to take, and their destination could be seen in real-time. And this also relates to the possibility to track people issue.

\section{IBeacon}

New technologies with possible impact on communication and public transport arrive quite often. New this year is the IBEACON technologies that Apple computer implemented in its operation system 7 for iphone and ipad units. (McFarland, 2014) It is a bluetooth based location recognition service. It enable mobile units to provide users to get relevant information when they come close to a sender.(Griffin, 2013)

Rogaland County made a similar "virtual reality" route in 2012. A scenic tourist route got signs along the road telling tourists which address to type on their phone, and then they could get a voice telling them about that location in several languages. The recent IBeacon technology can make such signs obsolete as the location of the user may push a similar message to the user provide the gadget have an app that is open for such information. Like a tourist may be told where to look for food or accommodation when approaching such offers. The IBeacon technology and similar may change or automate several functions in our surroundings. Examples may be automated payment as people access a bus or walk into a theatre, or registration as products in a supply-chain are passing a control-point. Location based apps may also be seen as a component in virtual reality and utilised in education. (Willem et al., 2012)

\section{Conclusion}

The rapid changing technologies in communication and related software provide us as users with more information at hand. This enables us to optimize our travels and thus may increase the use of public transport as waste of time in waiting may become reduced. Payment apps may also reduce the need for cash on busses and thus enable more efficient travels as seen from the driver.

We may expect several new location oriented apps that can inform tourists, students, or citizens about what to see and what to do, even inform about the 
offers of the day in next shop. This functionality may also change other software tools that do not include location relation now.

The perhaps most interesting issue is how these developments and their massive acceptance of the public may change public strategies from politicians or public planners. Related to public transport we may ask: Will such gadgets encourage more people to utilize public transport and therefore reduce rush-hour problems in urban areas and enable more frequent busses in rural areas?

\section{References}

ASIMOV, I. 1964. Visit to the World's Fair of 2014. New York Times, August 16, 1964.

EMMANOUILIDIS, C., KOUTSIAMANIS, R.-A. \& TASIDOU, A. 2013. Mobile guides: Taxonomy of architectures, context awareness, technologies and applications. Journal of network and computer applications, 36, 103-125.

FRICK, J. 2014. ITRACT [Online]. http://www.itract-project.eu. [Accessed 30 April 2014 2014].

GRIFFIN, D. E. T. 2013. Understanding tourists' spatial behaviour: GPS tracking as an aid to sustainable destination management. Journal of Sustainable Tourism, 21, 580-595.

GUBBI, J. 2013. Internet of Things (IoT): A vision, architectural elements, and future directions. Future generation computer systems, 29, 1645-1660.

INTERREG-IVB-NORTHSEA. 2014. North Sea Region Programme 20072013

http://www.northsearegion.eu/ivb/projects/details/\&tid=132: Interreg IVb North Sea.

JONES, E. C. \& CHUNG, C. A. 2011. RFID and AUTO-ID in Planning and Logistics, Boca Raton, FL, US, CRC Press.

KLEIN, B. 2014. User-Aware Management of Prosumed Micro-services. Interacting with computers, 26, 118-134.

MCFARLAND, M. 2014. How iBeacons could change the world forever. Washington Post, January 7th, 2014.

VOLKER STICH, TOBIAS BROSZE, FABIAN BAUHOFF \& FLORIAN GLÄSNER 2011. High Resolution Supply Chain Management - A Structural Model for Optimized Planning Processes based on RealTime Data. In: FRICK, J. \& LAUGEN, B. T. (eds.) Advances in Production Management Systems; Value Networks: Innovation, Technologies, and Management. 384 ed.: Springer.

WILLEM, C., BARTOLOMÉ, A., STEFFENS, K., FRICK, J., BOUWEL, S. V., KĘDZIERSKA, B., DÉTIENNE, F., CAWSTON, J., 
IBRAHIM, S., MARTÍNEZ, J., HUGGER, K.-U. \& GRANÉ, M. 2012. Avar+ : Audio-Visual Augmented Reality for Creative Learning. Work programme topic addressed ICT-2011.8.1 Technology-enhanced learning, d) Computational tools fostering creativity in learning processes. Barcelona: LMI, University of Barcelona. 